\title{
A Rare Axonal Variant of Guillain-Barré Syndrome as a Neurological Complication of COVID-19 Infection
}

\author{
Mojgan Agha Abbaslou, MD"; Maryam Karbasi, MD'; Hossein Mozhdehipanah, MD²* \\ ${ }^{1}$ Department of Internal Medicine, School of Medicine, Qazvin University of Medical Sciences, Qazvin, Iran \\ ${ }^{2}$ Department of Neurology, School of Medicine, Qazvin University of Medical Sciences, Qazvin, Iran
}

\begin{abstract}
Guillain-Barré syndrome (GBS) is a neurological disorder accompanied by several neurological signs and symptoms including progressive weakness and diminished or decreased reflexes. GBS was reported as one of the several neurological complications in MERS-CoV and SARS-CoV outbreaks. Several studies have reported GBS as a neurological complication in recent COVID-19 outbreak. We report on the case of a 55-years -old female who was hospitalized with dyspnea, dry cough, and myalgia. She developed Acute Motor \& Sensory Axonal Neuropathy (AMSAN), a rare variant of GBS signs and symptoms including decreased muscle strength and pinprick sensation in both lower extremities during her hospitalization.

Keywords: Axonal neuropathy, COVID-19, Dyspnea, Guillain-Barre syndrome, Muscle strength

Cite this article as: Agha Abbaslou M, Karbasi M, Mozhdehipanah H. A rare axonal variant of Guillain-Barré Syndrome as a neurological complication of COVID-19 infection. Arch Iran Med. 2020;23(10):718-721. doi: 10.34172/aim.2020.93.
\end{abstract}

Received: April 20, 2020, Accepted: July 15, 2020, ePublished: October 1, 2020

\section{Introduction}

An outbreak of coronavirus infection (COVID-19) was first reported in Wuhan, Hubei, China on December 31, 2019 and eventually spread throughout the world. ${ }^{1}$ The clinical characteristics of COVID-19 infection are previously described. ${ }^{2,3}$ Guillain-Barré syndrome (GBS) is a neurological disorder accompanied by several neurological signs and symptoms including progressive weakness and diminished or decreased reflexes ${ }^{4,5}$ GBS was reported as one of the several neurological complications in MERS-CoV and SARS-CoV outbreaks in 2004 and 2017, respectively. ${ }^{6,7}$ The first and only COVID-19 infection presenting with GBS as initial manifestation was reported by Hua et al. They reported acute weakness in both lower extremities and fatigue followed by decreased sensation to light touch and pinprick distally in a 61-yearold female as the initial presentation of COVID-19. ${ }^{8}$ In an observational series in Italy, Toscano et al. reported an association between GBS and COVID-19 infection.? Here, we report the case of a 55-year-old female who was hospitalized with dyspnea, dry cough, and myalgia. She developed GBS signs and symptoms including decreased muscle strength and pinprick sensation in both lower extremities during her hospitalization.

\section{Case Report}

A 55-year-old Iranian female was admitted to our general hospital after experiencing non-productive cough and myalgia for almost a week, followed by progressive dyspnea.
She also complained of several episodes of fever and chills five days prior to admission. She had a past medical history that was significant for an unknown chronic lung disease and oxygen dependency. She denied any alcohol or drug abuse and there was no history of smoking cigarettes.

Upon admission, the patient's oral temperature was $37.5^{\circ} \mathrm{C}, \mathrm{O}_{2}$ saturation was $56 \%$, pulse rate was 126 beats per minute, and blood pressure was $140 / 80 \mathrm{~mm} \mathrm{Hg}$. At that time, she denied any nausea, vomiting, abdominal pain, weakness in hands or legs, or impaired sensation. Computed tomography (CT) of her lungs displayed bilateral diffuse ground glass opacities (Figure 1) which was consistent with COVID-19 infection. ${ }^{10}$ The PCR for COVID-19 confirmed our diagnosis. Hydroxychloroquine (HCQ; $200 \mathrm{mg}$ twice a day) was initiated with other medicines including antiemetic, antipyretic, and $\mathrm{O}_{2}$ therapy. The patient was initially admitted to the internal medicine ward but then transferred to the intensive care unit (ICU) after experiencing progression of dyspnea. Kaletra (lopinavir/ritonavir) was started for her in the ICU two days after her admission. She was intubated five days later due to respiratory deterioration. Subsequently, her respiratory status began to improve and she was taken off the mechanical ventilator and transferred to the ward receiving $\mathrm{O}_{2}$ with mask $\left(\mathrm{O}_{2}\right.$ saturation: $\left.92 \%\right)$ twelve days after intubation. She described decreased muscle strength in her lower limbs four days after her transfer to the ward (26 days after hospitalization) as shown in Figure 2. On physical examination, muscle force in both lower limbs 


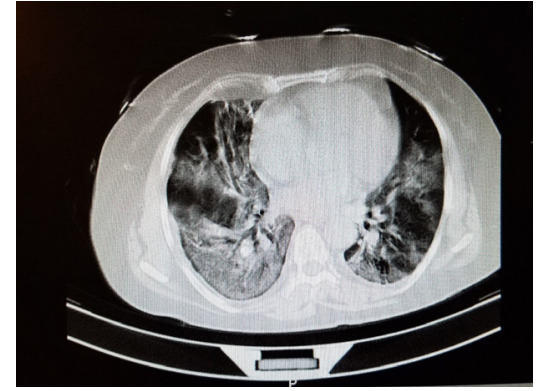

Figure 1. Lung CT Shows Bilateral Diffuse Ground Glass Opacities.

was 3 out of 5 using Medical Research Council (MRC) scale, pinprick sensation was decreased distally, and Deep Tendon Reflexes (DTRs) were absent. An electrodiagnostic test (EMG/NCV) was performed. The EMG/ NCV findings were suggestive of Acute Motor \& Sensory Axonal Neuropathy (AMSAN), a rare axonal variant of Guillain-Barré syndrome. ${ }^{11}$ Compound motor action potentials (CMAPs) and sensory nerve action potentials in the studied nerves were diminished or absent and no late response was seen, supporting the AMSAN variant of GBS (Tables 1 and 2). The cerebrospinal fluid (CSF) was also obtained and analyzed which was unremarkable with glucose: $78 \mathrm{mg} / \mathrm{dL}$, protein: 48,4 mg/dL (normal value: under $50 \mathrm{mg} / \mathrm{dL}$ ), and no white blood cells (WBCs). No bacteria were found in the CSF smear. We did not examine the CSF for detection of COVID-19. The Brighton Collaboration GBS Working Group criteria were used for GBS diagnosis. ${ }^{12}$ Given the diminished muscle strength in the patient's lower extremities, her NCV study results and CSF analysis, we established a diagnosis of GBS (the AMSAN variant) based on Brighton criteria levels 2 . Intravenous immunoglobulin was started for the patient but unfortunately, she passed away due to acute respiratory distress syndrome (ARDS) before the medication could start its effect.

\section{Discussion}

SARS-CoV-2, SARS-CoV and MERS-CoV are enveloped RNA viruses from the Alphacoronavirus and Betacoronavirus families. ${ }^{13}$ Several studies during previous outbreaks showed that these viruses have neurotrophic and neuroinvasive features. ${ }^{13-15}$ Arbour et al and Zumla et al in two separate studies in 2000 and 2015 reported that coronaviruses RNA can be found in the CNS of infected patients. ${ }^{13,14}$ Another study showed that MERS-CoV can infect human neural cells (NT2) in vitro. ${ }^{15}$ To date, there are few published data available regarding the neurological complications during treatment of infections caused by these viruses. In a retrospective study in 2017, Kim et al evaluated 23 MERS patients admitted to a single hospital in

Table 1. Motor Nerve Conduction Study

\begin{tabular}{|c|c|c|c|c|c|}
\hline Nerve and Site & Latency (ms) & Amplitude (mV) & Latency Difference (ms) & Distance $(\mathrm{mm})$ & Conduction Velocity $(\mathrm{m} / \mathrm{s})$ \\
\hline \multicolumn{6}{|l|}{ Left tibial } \\
\hline Ankle & Absent & Absent & Absent & Absent & Absent \\
\hline Popliteal fossa & Absent & Absent & Absent & Absent & Absent \\
\hline \multicolumn{6}{|l|}{ Left medial } \\
\hline Wrist & 3.6 & 2.1 & 3.6 & Absent & Absent \\
\hline Elbow & 7.7 & 1.1 & 4.1 & 200 & 49 \\
\hline \multicolumn{6}{|l|}{ Left peroneal } \\
\hline Ankle & Absent & Absent & Absent & Absent & Absent \\
\hline Fibula & Absent & Absent & Absent & Absent & Absent \\
\hline \multicolumn{6}{|l|}{ Right tibial } \\
\hline Ankle & Absent & Absent & Absent & Absent & Absent \\
\hline Popliteal fossa & Absent & Absent & Absent & Absent & Absent \\
\hline \multicolumn{6}{|l|}{ Right peroneal } \\
\hline Ankle & Absent & Absent & Absent & Absent & Absent \\
\hline Fibula & Absent & Absent & Absent & Absent & Absent \\
\hline
\end{tabular}

Ms, millisecond; $\mathrm{mV}$, millivolt ; $\mathrm{mm}$, millimeter; $\mathrm{m} / \mathrm{s}$, meter/second.

CMAPs of tibial and peroneal nerves were absent. There is reduced amplitude of median motor nerve. Peroneal \& Tibial F-waves and Tibial H-reflexes were absent on both sides (not shown above).

Table 2. Sensory Nerve Conduction Study

\begin{tabular}{lllllll}
\hline Nerve and site & Onset Latency $(\mathbf{m s})$ & Peak Latency $(\mathbf{m V})$ & Amplitude $(\mathbf{m s})$ & Distance $(\mathbf{m m})$ & Latency Difference $(\mathbf{m m})$ & Conduction Velocity $(\mathbf{m} / \mathbf{s})$ \\
\hline $\begin{array}{l}\text { Right sural } \\
\text { Lower leg }\end{array}$ & Absent & Absent & Absent & Absent & Absent & Absent \\
\hline
\end{tabular}

Ms, millisecond; $\mathrm{mV}$, millivolt; $\mathrm{mm}$, millimeter; $\mathrm{m} / \mathrm{s}$, meter/second.

The above examination shows no response in sural nerve. 


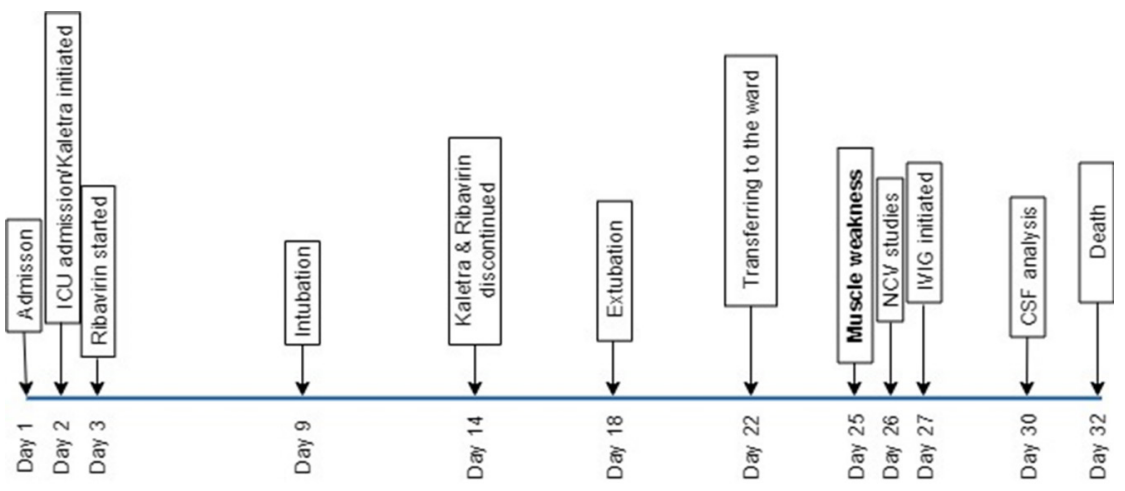

Figure 2. Timeline of Clinical Events in the Patient.

Korea for neurological complications during treatment. ${ }^{16}$ They reported Bickerstaff's encephalitis overlapping with GBS, alongside the drugs' side effects and ICU-acquired weakness in four patients. ${ }^{16}$ The authors concluded that understanding and evaluating neurological findings during treatment of these acute respiratory diseases is important because they may have been underdiagnosed or neglected. Interestingly, we only found one study reporting GBS as the initial manifestation of COVID-19. ${ }^{8}$ In contrast, our patient showed neurological signs and symptoms including symmetrical decrease in muscle strength in her lower limbs and weakness in both lower extremities approximately three weeks after her initial COVID-19 manifestations (Figure 2). Our findings are more consistent with the report by Kim et al that showed MERS neurological complications appear to be non-concomitant with respiratory symptoms. In the same study, neurological symptoms were delayed by 2-3 weeks. ${ }^{16}$ Our patient received Ribavirin and Kaletra (lopinavir/ritonavis) to treat COVID-19. Ribavirin is not associated with peripheral neuropathy. ${ }^{17}$ Kaletra can be a possible causative drug but the risk of peripheral neuropathy in patients receiving Kaletra is still unclear. ${ }^{18}$ Another possible cause for our patient's neurological complications is critical illness neuropathy. ${ }^{19}$ However, given the short intubation time (11 days) and the fact that our patient's symptoms started three days after ICU discharge, this would be a poor possibility.

CSF analysis in patients with GBS shows high protein levels and normal WBC. ${ }^{20}$ Protein levels increase by the end of the second week of initiation of GBS signs and symptoms in $90 \%$ of patients. However, the protein levels may be normal in the early stage ${ }^{20}$ similar to what we observed in our patient and Tocano et al reported in their study. ${ }^{9}$ Our patient showed progressive respiratory deterioration and ARDS which led to her death seven days after the initial GBS symptoms. Whether the patient's ARDS and death was a fatal complication of COVID-19 infection $^{21}$ or a result of her unknown chronic lung disease or GBS progression, is a topic that needs further investigation.
While we were preparing this study, several other studies around the world also reported similar findindgs in patients following COVID-19 infection. ${ }^{22-26}$ Our study reports AMSAN, a rare variant of GBS in a patient following COVID-19 infection.

In conclusion, our study and other similar studies suggest that care providers should be aware of newly developed neurological symptoms and/or signs in COVID-19 patients, especially those hospitalized. More studies could be helpful to increase our knowledge about neurological manifestations of COVID-19 and guide our investment in more effective therapies.

\section{Authors' Contribution}

MAA and MK: study design, data collection, manuscript preparation and literature search. HM: Study design, data interpretation and manuscript preparation.

\section{Conflict of Interest Disclosures}

All authors declared no conflict of interest.

\section{Ethical Statement}

This case report is reviewed and evaluated at national committee for ethics in biomedical research and it is registered at: http://ethics. research.ac.ir, with the ethical code of 1399.013 .

\section{References}

1. Wang C, Horby PW, Hayden FG, Gao GF. A novel coronavirus outbreak of global health concern. Lancet. 2020;395(10223):470-3. doi: 10.1016/S0140$6736(20) 30185-9$.

2. Huang C, Wang Y, Li X, Ren L, Zhao J, Hu Y, et al. Clinical features of patients infected with 2019 novel coronavirus in Wuhan, China. Lancet. 2020;395(10223):497-506. doi: 10.1016/S0140-6736(20)30183-5.

3. Li Q, Guan X, Wu P, Wang X, Zhou L, Tong Y, et al. Early transmission dynamics in Wuhan, China, of novel coronavirusinfected pneumonia. N Engl J Med. 2020;382(13):1199-207. doi: 10.1056/NEJMoa2001316.

4. Asbury AK, Cornblath DR. Assessment of current diagnostic criteria for Guillain-Barré syndrome. Ann Neurol. 1990; 27(suppl):S21-S24. doi: 10.1002/ana.410270707.

5. Van der Merché FG, Van Doorn PA, Meulstee J, Jennekens FG. GBS-consensus group of the Dutch Neuromuscular Research Sipport Centre. Diagnostic and classification criteria for the Guillain-Barré syndrome. Eur Neurol. 2001;45(3):133-9. doi: 
10.1159/000052111.

6. Tsai LK, Hsieh ST, Chao CC, Chen YC, Lin YH, Chang SC, et al. Neuromuscular disorders in severe acute respiratory syndrome. Arch Neurol. 2004;61:1669-73. doi: 10.1001/ archneur.61.11.1669.

7. Kim JE, Heo JH, Kim HO, Song SH, Park SS, Park TH, et al. Neurological complications during treatment of middle east respiratory syndrome. J Clin Neurol. 2017;13(3):227-33. doi: 10.3988/jcn.2017.13.3.227.

8. Zhao H, Shen D, Zhou H, Liu J, Chen S. Guillain-Barré syndrome associated with SARS-CoV-2 infection: causality or coincidence?. Lancet Neurol. 2020;19(5):383-4. doi: 10.1016/S1474-4422(20)30109-5.

9. Toscano G, Palmerini F, Ravaglia S, Ruiz L, Invernizzi P, Cuzzoni GM, et al. Guillain-Barré Syndrome Associated with SARS-CoV-2. N Engl J Med. 2020;382:2574-6. doi: 10.1056/ NEJMc200919.

10. Shi H, Han X, Jiang N, Cao $Y$, Alwalid O, Gu J, et al. Radiological findings from 81 patients with COVID-19 pneumonia in Wuhan, China: a descriptive study. Lancet Infect Dis. 2020;20(4):425-34. doi: 10.1016/S1473-3099(20)300864.

11. Dimachkie MM, Barohn RJ. Guillain-Barré syndrome and variants. Neurol Clin. 2013;31(2):491-510. doi: 10.1016\%2Fj. ncl.2013.01.005.

12. Sejvar JJ, Kohl KS, Gidudu J, Amato A, Bakshi N, Baxter R, et al. Guillain-Barré syndrome and Fisher syndrome: case definitions and guidelines for collection, analysis, and presentation of immunization safety data. Vaccine. 2011;29(3):599. doi: 10.1016/j.vaccine.2010.06.003.

13. Zumla A, Hui DS, Perlman S. Middle East respiratory syndrome. The Lancet. 2015;386(9997):995-1007. doi: 10.1016/S01406736(15)60454-8.

14. Arbour N, Day R, Newcombe J, Talbot PJ. Neuroinvasion by human respiratory coronaviruses. J Virol. 2000;74(19):891321. doi: 10.1128/JVI.74.19.8913-8921.2000.

15. Chan JF, Chan KH, Choi GK, To KK, Tse H, Cai JP, et al. Differential cell line susceptibility to the emerging novel human betacoronavirus 2c EMC/2012: implications for disease pathogenesis and clinical manifestation. J Infect Dis. 2013;207(11):1743-52. doi: 10.1093/infdis/jit123.

16. Kim JE, Heo JH, Kim HO, Song SH, Park SS, Park TH, et al. Neurological complications during treatment of middle east respiratory syndrome. J Clin Neurol. 2017;13(3):227-33. doi: 10.3988\%2Fjcn.2017.13.3.227.

17. Khiani V, Kelly T, Shibli A, Jensen D, Mohanty SR. Acute inflammatory demyelinating polyneuropathy associated with pegylated interferon $\alpha 2$ a therapy for chronic hepatitis $C$ virus infection. World J Gastroenterol. 2008;14(2):318-21. doi: $10.3748 \% 2$ Fwjg. 14.318.

18. Ellis RJ, Marquie-Beck J, Delaney P, Alexander T, Clifford DB, McArthur JC, et al. Human immunodeficiency virus protease inhibitors and risk for peripheral neuropathy. Ann Neurol. 2008;64(5):566-72. doi: 10.1002/ana.21484.

19. Saccheri C, Morawiec E, Delemazure J, Mayaux J, Dubé BP, Similowski T, Demoule A, Dres M. ICU-acquired weakness, diaphragm dysfunction and long-term outcomes of critically ill patients. Ann Intensive Care. 2020;10(1):1. doi: 10.1186\%2Fs13613-019-0618-4.

20. Walling AD, Dickson G. Guillain-Barré syndrome. Am Fam Physician. 2013;87(3):191-7

21. Jiang F, Deng L, Zhang L, Cai Y, Cheung CW, Xia Z. Review of the clinical characteristics of coronavirus disease 2019 (COVID-19). J Gen Intern Med. 2020:1-5. doi: 10.1007/ s11606-020-05762-w.

22. Kilinc D, van de Pasch $S$, Doets $A Y$, Jacobs BC, van Vliet J, Garssen MP. Guillain-Barré syndrome after SARS-CoV-2 infection. Eur J Neurol. 2020;27(9):1757-8. doi: 10.1111/ ene. 14398

23. Sedaghat Z, Karimi N. Guillain Barre syndrome associated with COVID-19 infection: a case report. J Clin Neurosci. 2020;76:233-5. doi: 10.1016/j.jocn.2020.04.062.

24. Sancho-Saldaña A, Lambea-Gil Á, Liesa JL, Caballo MR, Garay $\mathrm{MH}$, Celada DR, et al. Guillain-Barré syndrome associated with leptomeningeal enhancement following SARS-CoV-2 infection. Clin Med. 2020;20(4):e93-4. doi: 10.7861/ clinmed.2020-0213.

25. Dalakas MC. Guillain-Barré syndrome: The first documented COVID-19-triggered autoimmune neurologic disease: More to come with myositis in the offing. Neurol Neuroimmunol Neuroinflamm. 2020;7(5):e781. doi: 10.1212/ NXI.0000000000000781.

26. Caamaño DS, Beato RA. Facial diplegia, a possible atypical variant of Guillain-Barré Syndrome as a rare neurological complication of SARS-CoV-2. J Clin Neurosci. 2020;77:230232. doi: 10.1016/j.jocn.2020.05.016. 